\title{
CRAFTING A STRATEGY FOR IMPROVED COMMUNAL WASTE MANAGEMENT IN MAFIKENG
}

\author{
F.R.K. KADAMA \\ North West University, South Africa.
}

\begin{abstract}
The study investigated and evaluated the alternative methods for implementing proposed changes at communal waste collection points in Mafikeng (Mahikeng) city. In doing so, the study was cognisant of the constitutional requirement for municipalities to ensure the well-being of the citizenry by protecting the environment and was also cognisant of the fact that municipalities had to operate within the ambit of the law. It was established that the provisions in the Municipal Finance Management Act (Republic of South Africa) empowered and provided guidelines for the Mafikeng Local Municipality to implement the proposed changes. An analysis of the variables in the waste management system revealed that the best way forward was for the Mafikeng Local Municipality to implement the proposed changes is through a public-private partnership with a reputable organisation from the formal private sector. Several recommendations, including the involvement of the public in the change process, were made for the success of the partnership.

Keywords: capital budgeting, internal rate of return, net present value, payback, waste management.
\end{abstract}

\section{INTRODUCTION}

Mafikeng (Mahikeng) is the capital city of the North West (NW) province of South Africa. It is situated approximately $35 \mathrm{~km}$ from the Ramatlabama border with Botswana, which is the gateway to Gaborone and Namibia. The city covers about $927 \mathrm{~km}^{2}$ [1], and its population has steadily increased since 1996. Available statistics indicate that the population increased from 43,395 in 1996 to 47,887 in 2001, while the number of households increased from 11,679 to 15,921 during the same period $[2,3]$. From these statistics, the respective annual growth rates were computed as $2 \%$ and $7 \%$. The city is administered by the Mafikeng City Council (MCC), which provides its residents with municipal services, such as waste removal, street lighting, water, electricity, sewerage services and storm water drainage [3]. Unlike other urban authorities in the NW, which provide only curb-side waste services, MCC also provides communal waste collection (CWC) services for garden waste in residential areas [4]. Operations at the community waste collection points pose a number of problems as elaborated in the background to the study and the problem statement.

\subsection{Background}

This paper is an expansion of Kadama [4] which highlighted the problems experienced in Mafikeng as a result of malpractices at CWC points. The problems cited include excessive littering around CWC points, air pollution and the degradation of surrounding areas through burning and denudation of soil cover. Kadama [4] also noted that not only were the city by-laws ineffective under the circumstances but also MCC lacked resources to act against transgressors. Consequently, environmental and socio-economic impacts, such as health hazards, reduction in property value and aggravated communities venting their frustration by disrupting socio-economic order have become the order of the day.

In an attempt to arrest the deteriorating situation at CWC points, the city council acquired tractor loader backhoes (TLB) and tipper trucks to clean up at CWC points. According to Kadama [4], these capital acquisitions required a large capital outlay that had not been planned for originally. Given the 


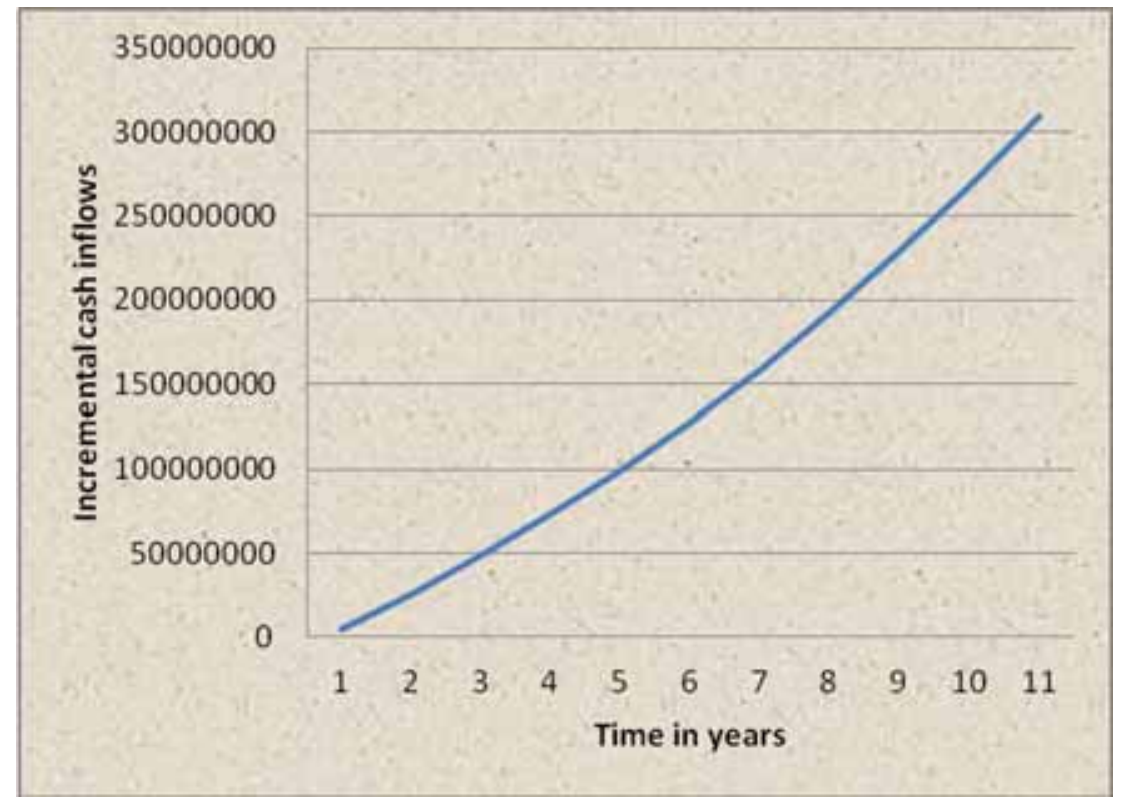

Figure 1: Incremental cash inflows for Investments 1 and 2. Source: Kadama [4].

circumstances, one tends to infer that the city council had to divert resources intended for other priority areas to attend to the deteriorating situation at CWC points. Site visits to CWC points in Mafikeng and the continuous public outcry in the media noted in Kadama [4] suggest that the interventions by the city council have not yielded the desired results. The city council attributes the failure to its underestimation of the volume of waste involved and inadequate equipment that often breaks down.

In a 10-year projection analysis of two investment scenarios (Investments: I and II), one evaluating the current practice at CWC points in Mafikeng and the other a proposed alternative, Kadama [4] demonstrates that there would be positive incremental cash inflows if the present practice were to be replaced. Positive incremental cash inflows indicate added value. This analysis is illustrated in Fig. 1.

In Fig. 1, it is observable that the incremental operating cash inflows for Investments 1 and 2 were positive throughout the period of projection. It is also observable that the incremental inflows exponentially increased with time. This outcome indicates that replacing Investment 1 with Investment 2 would add value to the operations of the city and the benefits would progressively increase in value.

\subsection{Problem statement}

Whereas the financial analysis in Kadama [4] justifies the need for a change in tactical strategy, it does not address the manner in which it should be implemented. A review of literature in section 2 reveals a number of options available for the MCC to choose from. Decision making becomes a problem when there are two or more possible courses of action. There is, therefore, a need to to critically evaluate available options and select the one that would most effectively address the inefficiencies of high costs and poor quality of waste management experienced in Mafikeng. 


\subsection{Aim and objectives}

Having recognised the need for change in the tactical strategy at CWC points and the incremental benefits that would arise as a result of adopting the design proposed in Kadama [4], this paper aimed at exploring the options of implementing change that were available to MCC. The specific objectives were to:

1. Assess available options for implemeting change with a view of selecting the most appropriate option.

2. Determine the economic viablity of the chosen option. In pursuits of these objectives, this paper addressed the following questions;

a. Is there a framework to guide the proposed change in strategy?

b. What options does MCC have to implement the proposed change in strategy?

c. Which option is most appropriate for MCC?

d. Is the proposed change in strategy economically feasible?

\section{LITERATURE REVIEW}

The Constitution of the Republic of South Africa [5], prescribes that everyone has the right to a healthy environment and to have the environment protected for the benefit of the present and future generations. These prescripts are operationalised by a number of acts of parliament, which include the National Environmental Management Act [6] and the Municipal Finance Management Act [7]. Jointly, these acts of parliament prescribe the role players in waste management and provide guidelines for execution of activities in waste management.

\subsection{Need for change and guidelines thereto}

Municipal service delivery in South Africa is below par, when compared to international best practice. Cognisant of this fact, the Municipal Finance Management Act [7] advocates the need for change and outlines a set of principles and alternative options for a more effective service delivery. It calls on municipalities to strategically assess and plan for the most appropriate forms of service delivery for their areas and implement the chosen options in the most cost-effective manner so as to ensure maximum benefit for their communities. For this call to be realised, the Municipal Finance Management Act [7] suggests that in choosing delivery options, municipalities should be guided by the following principles:

1. Accessibility of services to all citizens without discrimination.

2. Affordability of services to the municipalities.

3. Quality of products and services, which includes attributes, such as suitability of purpose, timeliness, convenience, responsiveness to end users, safety and continuity.

4. Accountability of services.

5. Adoption of an integrated approach to development which takes into account the economic and social impacts of the service on offer.

6. The chosen option should be financially viable and environmentally sound.

7. Obtain value-for-money from end product or service as a way of ensuring the best use of public resources.

8. Promote competitiveness of local commerce and industry.

9. Uphold the democratic principles enshrined in the constitution. 


\subsection{Options for implementing the proposed change}

The Municipal Finance Management Act [7] is not prescriptive on the options that municipalities need to adopt to implement change. However, it provides the following as possible options to choose from:

1. Building on existing in-house capacity.

2. Corporatisation or establishing semi-autonomous units within the municipal councils.

3. Public-public partnerships in the form of joint ventures with other municipalities.

4. Contracting out to specialist private companies to provide particular aspects of the service.

5. Public-private partnerships (PPPs) in form of long-term leases.

6. Privatisation that would involve the transfer of ownership of municipal assets as well as the responsibility to manage delivery of the entire service to a private company.

It is therefore every municipality's responsibility to select the most suitable service delivery option or mix, which most effectively achieves their policy objectives.

\subsection{Agenda for action}

In developing countries, high levels of service delivery in solid waste management and maximum benefits are usually realised only when municipalities participate with other sector role players [8-10]. In the literature surveyed, the following were identified as the main role players associated with successful multi-sector partnerships in solid waste management in developing countries:

1. Municipalities;

2. Formal private sector;

3. Informal private sector and

4. Community-based organisations ( $\mathrm{CBO})$ and non-governmental organisations (NGO).

The pivotal point in multi-sector partnerships in waste management is the acceptance that the overarching responsibility and mandate of municipalities remains central, irrespective of the extent to which they succeed in referring their tasks to other role players [7].

Joint participation in solid waste management introduces changes that improve operational efficiency. According to Cointreau-Levine and Coad [8] and Hilgendorff [11], solid waste management stands to improve if the following changes are implemented:

1. Upgrading the human resource knowledge and skills base.

2. Improvement and maintenance of infrastructure and machinery.

3. Rationalisation of operations.

4. Accountability.

They aver that the realised efficiency derives from the following attributes that accrue as a result of the implementation of changes:

1. The obligation of accountability to customers.

2. Inspiration fuelled by the element of competition.

3. Performance targets prescribed in contracts. 
4. Flexibility to
a. hire competent staff;
b. remunerate staff according to performance;
c. terminate non-performers and
d. adjust shift periods according to service demand.

5. Minimal bureaucratic entanglements.

6. Minimal political interference.

Shafiul and Syed [12] estimate the global urban solid waste generation to have been about 1.6 billion tonnes in 2005 and this figure was expected to increase annually due to increasing urban migration. They note that while cities in developed countries had the financial resources and technical skills to handle their solid waste burden, municipalities in developing countries lacked the wherewithal to handle the complexity of solid waste management. Consequently, they posed the question of how to deliver quality service in the face of financial and skills constraints of the public sector. It is important for municipalities in developing countries to assess their capacity by conducting environmental audits. It is important to note that ignoring the shortcomings of municipalities in delivering quality waste management not only poses a health risk but also comes with serious environmental impacts that require costly remedial action. Shafiul and Syed [12] aver that the solution to the lack of resources and waste management skills in municipalities lies in the formal involvement of the public sector and the private in solid waste management. Such arrangements involving the private sector, the general public and government institutions are commonly referred to as (PPPs). In PPPs, the private sector infuses the dynamism and flexibility associated with it into the operations of the entities. This helps to bridge the gap in service delivery and improve on accountability and reporting protocols.

A PPPs is a joint venture funded and operated through a partnership of government and one or more private sector companies. According to Wikipedia [13], a PPP involves a contract between a public sector authority and a private sector party in which the latter provides a public service and assumes substantial financial, technical and operational risk in the project. Wikipedia [13] identifies the following variants in PPP:

1. The private sector secures capital financing on the strength of a contract with the government to provide agreed services and the recipients of the service bear the entire cost of the service.

2. The private sector secures capital financing on the strength of a contract with the government to provide agreed services and the cost of providing the service is borne by the government.

3. Government's contribution to a PPP may partly be in kind through the transfer of existing assets.

4. Government may support the project by providing revenue subsidies, including tax breaks or by providing guaranteed annual revenues for a fixed period.

According to PPP unit [14], the national treasury of South Africa prescribes the three types of PPP arrangements listed below:

1. A private party secures $100 \%$ private funding and performs an institutional or municipal function.

2. A private party uses public funds and assets to perform an institutional or municipal function.

3. A private party combines private funding and state assets to perform municipal activities.

This study opted for the second option where a private partner secures private funding, builds the necessary infrastructure and is paid by the municipality for services rendered. The choice was based on the assumption that where government is the buyer of a service, and insofar as the service is 
provided to the agreed standards, there is a steady revenue stream to the private party thereby reducing their risk exposure.

2.4 Main participants in solid waste management and the characteristics of their roles

The main participants in solid waste management and the characteristics that typify their roles are summarised in Table 1.

\subsection{Challenges to multi-sector partnerships in solid waste management}

Lardinois and Klundert [9] and Kadama [15] identify a number of challenges that have been experienced in the development of multi-sector partnerships. These include:

1. Financial constraints especially with regard to

a. Municipalities being constrained by strict regulations governing public funds.

b. Ineffective revenue collection systems.

c. Operations of the formal private sector frustrated by lack of capacity, credibility and resilience.

d. High-risk exposure resulting in high-risk management costs for the formal private sector.

e. The informal private sector constrained by limited access to funding.

f. Awarding short-term contracts that limit the investors' post-breakeven point operating period. Such arrangements leave investors with no choice but to invest in mediocre vehicles and equipment, which results in ineffectiveness and inefficiency.

2. Institutional and capacity problems common to developing countries, such as

a. No felt need among municipalities to work with the private sector or citizens.

b. There is a lack of effective by-laws on waste management to guide municipalities.

c. Lack of funds for NGOs and CBOs that would advocate for waste management PPP.

Table 1: The main participants in solid waste management and the characteristics of their roles.

\begin{tabular}{ll}
\hline Participants & \multicolumn{1}{c}{ Characteristic roles } \\
\hline Municipalities & 1. Address legal and political concern. \\
& 2. Uphold public stature. \\
3. Fulfil mandated obligations. & 4. Use of public funds generated from tax and service fee collections. \\
5. Contract with the private sector. & 1. Profit motivated. \\
Formal private sector & 2. Perform activities because of their potential to generate income. \\
& 3. Use private resources involving high capital input. \\
4nformal private sector & $\begin{array}{l}\text { 1. Motivated by subsistence and survival instincts. } \\
\text { 2. Driven to satisfy needs. }\end{array}$ \\
3. Meagre capital outlay in comparison to the formal sector. \\
4. Regarded as a nuisance by municipal authorities. \\
1. Motivated by a desire to improve the lot for communities. \\
2. Solicit outside resources and donor funds. \\
3. Not profit-oriented.
\end{tabular}

Source: Cointreau-Levine and Coad [8] and Lardinois and Klundert [9]. 
3. Flawed tendering processes that result in private operators being awarded contracts on the basis of patronage rather than competence.

4. Resistance from the informal private sector who are threatened by the possibility of extinction as a result of contractual partnerships.

5. Animosity between formal and informal private sector operators, which stems from competition.

6. Inappropriate technology and designs at existing waste management facilities.

7. Increasingly high labour costs resulting in incessant wage disputes.

From the above, it is clear that many challenges need to be addressed before multi-sector partnerships in solid waste management can be successfully established. A partnership should be considered only when it can, on the overall, contribute to making waste management more environmentally responsive, efficient and economical [9]. Since private sector partners are profit-motivated, longterm partnership contracts are necessary for investors to recoup their costs and make profit. Given that municipalities are custodians of public interests, service delivery agreement should be drafted with their consultation. NWU [16] suggests that the service agreements must:

1. Comply with the provisions of relevant laws and by-laws.

2. Be available to the public.

3. Establish all conditions of the service.

4. Provide for the circumstances under which the municipality may prohibit the service provider from offering the service and resume service provision itself.

5. Detail all conditions and remedies the municipality will have in the event of default by the service provider.

Therefore, municipalities should act cautiously to select only the best for long-term partnerships. The PPP contracts should be concise on technical specifications, performance monitoring and penalties for poor performance.

\subsection{Justification of partnerships in solid waste management}

This section reviews the work of Lardinois and Klundert [9] and Barton, Leite, and Schertenleib [17] and Schubelar, Wehrle and Christen [18] and summarises some of the possible benefits that accrue from partnerships with different role players. It should be noted that the realisation of these advantages depends on the capacity of the role players and the oversight ability of the municipalities. The discussion considers how partnerships between the different role players would benefit:

1. The waste management systems.

2. The local economy.

3. The environment.

2.6.1 Potential benefits from the formal private sector

The possible benefits with regard to the waste management systems include:

1. Enhanced performance and efficiency stemming from leaner organisations and flexibility to higher competent staff and to review compensation procedures.

2. A high commitment to accountability.

3. Prompt response and shorter lead time associated with the process of raising private capital as opposed to the relatively long lead times involved with government decision-making and donor grant applications. 
4. High work ethics associated with the drive to attract and maintain clients.

5. Relatively greater flexibility to acquire assets and replace equipment.

6. Ability to access expertise and technology due to the ease with which the formal private sector may form local and foreign networks.

7. Ability to transfer risk.

The possible benefits to the local economy include:

1. Emergence of a robust commercial sector.

2. Creation of permanent and sustainable jobs.

3. Material recovery through recycling thus reducing both local and foreign exchange expenditure on acquisition of material.

On the socio-environmental front, the possible benefits include:

1. Minimisation of political patronage in waste management activities.

2. Conservation of resources as a result of material recovery.

3. Less environmental degradation due to a reduction in the exploitation of primary resources, including mining and deforestation.

2.6.2 Potential benefits from the informal private sector

The informal private sector comprises small to micro entrepreneurs, families and individuals. Due to the large numbers involved, their activities have a marked impact on waste management systems. The potential benefits from their activities include:

1. The processing of large volumes of waste at marginal cost to the municipalities.

2. Reduction of municipalities' transport burden.

3. Reduction of throughput to landfills thereby extending their lifetime.

4. Extension of waste services to areas not serviced by municipalities.

The informal private sector also has an impact on the local economy. Possible benefits to the local economy that accrue from their activities include:

1. The supply of raw materials to local recyclers at competitive rates.

2. Providing stimuli for industrial production.

3. Being a source of income for a large number of households in the low-income strata.

4. Supplying reusable items, such as containers and used mattresses, to low-income households at reasonable prices.

The activities of informal private also impact on the social aspects and the environment as a whole. Possible resultant benefits include:

1. Providing livelihood for a large number of citizens who are otherwise unemployable in the formal job market.

2. Conservation of resources as a result of material recovery.

3. Less environmental degradation due to a reduction in the exploitation of primary resources, including mining and deforestation. 


\subsubsection{Potential benefits from CBOs and NGOs}

The emergence of CBOs and NGOs in developing nations and their participation in waste management has resulted in numerous tangible benefits. The increasing role of CBOs and NGOs in waste management promises yet more benefits. The actual and possible benefits to the waste management system include:

1. Capacity building through the provision of infrastructure and material resources.

2. Human resource training.

3. Injecting donor funds into the system.

4. Mobilisation of citizens and encouraging their participation in waste management activities.

5. Promotion of environmental awareness.

6. Provision of environmental health education.

7. The extension of waste management services to areas not covered by municipalities.

Through their role in capacitating the waste management sector, CBOs and NGOs continue to contribute to the local economies by

1. improving the quality and quantity of recovered material and

2. empowering participants in waste management to become more efficient.

The participation of CBOs and NGOs in waste management in developing countries has thus far left an indelible mark in the social chronicles. Their involvement has yielded and promises to yield even more benefits on the social scene and to the environment. Such benefits include:

1. Providing support in terms of advocacy and technical assistance to the informal private sector.

2. Levelling the playing field in waste management by providing countervailing power in favour of the informal private sector.

3. Exposure of the informal private sector to new income-generating activities.

4. Strengthening the organisational capacities of the informal private sector and entrepreneurs.

\subsection{Making capital investment decisions}

Private sector organisations are profit motivated. It is important for them to ensure that the capital decision they make would have a positive impact on the value of stock. Any firm that considers providing CWC services for MCC as proposed in Kadama [4] has to commit its scarce resources to acquire assets and establish infrastructure. These non-current asset investments will be long term and not easily reversible. The decisions on what non-current assets to invest in falls under the study of capital budgeting. There are a number of techniques that are used to determine whether a particular investment will result in added value. This section reviews the capital budgeting techniques that were used to determine the economic viability of the option suggested in Kadama [4].

\subsubsection{Payback period}

Payback is the time taken for an investment to recover its initial cost from the cash flows it generates. A capital investment is acceptable if the payback period is shorter than a specified period. Payback is the accounting breakeven point [19]. One may therefore infer that the shorter the payback period, the better the investment. However, it may not be wise to select an investment on the basis of a short payback period for the reason that this method does not take the time value of money into account 
and does not consider cash flows subsequent to the payback period $[19,20]$. The payback assessment tends to favour projects that free cash quickly for use in other ventures and may be biased against long-term investments.

\subsubsection{Discounted payback period}

The discounted payback period is the time taken for an investment's discounted cash flows to equalise with the investment cost. Each future cash flow is discounted by the required rate of return of the investment. As such, the discounted payback period is the financial breakeven point as it represents the time it takes for one to get back their money along with the interest they could have earned if they had invested elsewhere [19]. However, Firer et al. [19] admonish that the discounted payback rule has drawbacks, the most significant being that the cut-off is arbitrarily set and cash flows beyond that point are ignored. As a result, projects with less value may be selected over those that would have been more beneficial to the shareholders. For that matter, this review investigated the net present value (NPV) technique which is considered to be a more rigorous metric for evaluating the feasibility of investments.

\subsubsection{Net present value}

The difference between an investment's market value and its cost is called its NPV. It is a measure of how much value is created through an investment [19]. According to Brigham and Gapenski [20], the NPV is determined using the discounted cash flow method, which is implemented as follows:

1. Determine the present value of each projected cash flows (inflows and outflows) by discounting them at the cost of capital charged to the venture.

2. Sum the discounted cash flows to obtain the NPV.

3. Accept projects with positive NPV and reject those with negative NPV.

4. For mutually exclusive projects, select project with highest NPV.

Reference [20] provide an insight of what NPV signifies:

1. An NPV of zero indicates that the project's cash flows just suffice to recoup the invested capital and provide the required rate of return on that capital. If a firm takes on a zero NPV project, its operations increase in volume but the price of its shares remain the same.

2. A positive NPV indicates that the project's cash flows are able to generate excess returns. Excess returns accrue to shareholders and the price of the share increases. Eqn (1) [20] is used to represent NPV:

$$
N P V=\sum_{t=0}^{n} \frac{C F_{t}}{(1+k)^{t^{\prime}}}
$$

where

$C F_{t}=$ The expected cash flow at period $t$.

$K=$ The project's periodic cost of capital.

$T=$ Period taken.

$n=$ Factors.

To determine the NPV, one may use a spreadsheet, such as MS Excel, or use a financial calculator.

\subsubsection{Internal rate of return}

The internal rate of return (IRR) is the discount rate that equates the NPV of an investment to zero. At NPV $=0$, the shareholders' wealth does not change in value. A project should be accepted if its 
IRR is greater than its required rate of return [19]. According to Brigham and Gapenski [20], the IRR on a project is its expected rate of return. For that matter, they argue, if a project's IRR is greater than its cost of capital, surplus remains after paying off its debt and accrues to the shareholders. On the other hand, taking on a project whose IRR is less than its cost of capital imposes a cost on shareholders. Eqn. (2) [20] is used to represent IRR:

$$
\operatorname{IRR}=\sum_{t=0}^{n} \frac{C F_{t}}{(1+r)^{t}}=0
$$

where

$C F_{t}=$ The expected cash flow at Period $t$.

$r=$ Return.

$t=$ Period taken.

$n=$ Factors.

\section{RESEARCH METHOD}

To achieve the objectives of the study, the following procedures were followed:

1. Desktop studies were undertaken to gather the information required for objectives 1 and 2 .

2. A matrix was developed to evaluate the ability of the different role players in waste management to implement the proposed change in waste management. The ability to deliver with regard to a set of attributes was rated on scale of 1-5, where the numbers represented the following descriptions: 1 - never, 2 - seldom, 3 - sometimes, 4 - often and 5 - always.

3. The discounted payback period, NPV and IRR assessment metrics were applied to determine the economic viability of the proposed option. The procedures described in sections 2.7.1 and 2.7.2 were followed to determine the payback period and NPV, respectively. An MS Excel spreadsheet and a Sharp EL 733A financial calculator were used in the process. The cost of capital for the proposed project was assumed to be $10 \%$ and for that matter its cash flows were discounted at a rate of $10 \%$.

\section{RESULTS}

The findings of this study are presented in the order of the research questions in section 1.3.

4.1 Is there a framework to guide the proposed change in strategy?

The desktop survey established that there exists a framework to guide the MCC on how to implement the proposed strategy. These guidelines are contained in Municipal Finance Management Act [7]. The Act advocates for a change in the modus operandi in service delivery by municipalities and provides a set of guidelines for implementing the changes. These guidelines are listed in section 2.2 of this paper.

\subsection{What options does MCC have to implement the proposed change in strategy?}

The study also established that the Municipal Finance Management Act [7] is not prescriptive on how municipalities are expected to implement changes in waste management. The Act outlines possible options for municipalities to choose from which are listed in section 2.2 of this paper. 


\subsection{Which option is most appropriate for MCC?}

In section 2.3, the survey identified the main role players in waste management. These were then evaluated on the basis of their ability to perform with regard to a set of desired attributes listed in section 2.3 and presented in Matrix 1. The role players were rated as described in section 3. The score was tallied and the role player with the highest became the preferred option.

Matrix 1: An evaluation of the ability of role players in waste management to implement the proposed change.

In the evaluation, the formal private sector emerged with the highest score (42 out of 45) and was deemed to be the best suited to implement the proposed change in MCC.

\subsection{Is the proposed change economically feasible?}

Three financial metrics: discounted payback analysis, NPV and IRR were applied to assess the economic viability of the proposed project. A discounted payback analysis of 10 years cash flow projections of the proposed project is presented in Table 2.

The discounted cumulative cash flows in Table 2 show that the proposed project will break even in the fourth year. This is illustrated in Fig. 2. The intersection of total expenditure and cash flows represents the discounted breakeven point. From the graph, one can estimate that breakeven occurs in the second half of the third year.

Considering that the venture is expected to last for 10 years, a discounted payback period of less than 4 years is good enough for the shareholders. It is highly likely that when approached for funds, financiers will positively consider this point as they assess the application.

The NPV and IRR of the project were determined in two ways:

1. An Ms Excel spreadsheet template gave values of NPV $=\mathrm{R} 7,286,485.69$ and IRR $=65 \%$.

2. A Sharp financial calculator gave values of NPV $=\mathrm{R} 8,618,493.88$ and $\mathrm{IRR}=45.33 \%$. The discrepancy observed in the values of NPV and IRR obtained by the different methods arose due to the fact that the calculator did not factor in the cost of capital in its computation. Given that the proposed project is expected to use borrowed capital, the NPV and IRR values obtained using the MS Excel spreadsheet should be adopted for this study. However, should it happen that the organisation that wins the bid for this project prefers to fund it using owner's equity only, then one would use the two sets of metrics to prove to them that their equity would earn more returns if they also use debt financing.

\section{DISCUSSION AND RECOMMENDATIONS}

The study established that the government of South Africa has put in place the necessary laws in the form of acts of parliament and has also provided guidelines for implementing the proposed change in MCC. However, it should be noted that whereas acts of parliament are enabling laws, they do not address all the specific activities associated with waste management at the local municipality level. In order for local municipalities to efficiently deliver waste services, they need to develop and pass effective waste management by-laws. Mafikeng Local Municipality, just like many other local municipalities in the NW, lacks effective by-laws on waste management [15]. It is, therefore, recommended that the Mafikeng Local Municipality reviews and bolsters the by-laws on waste management. The municipality is advised to adapt the draft standard by-laws of the NW [16]. The procedure for municipalities to adopt by-laws is outlined in section 12 of Republic of South Africa [6]. 


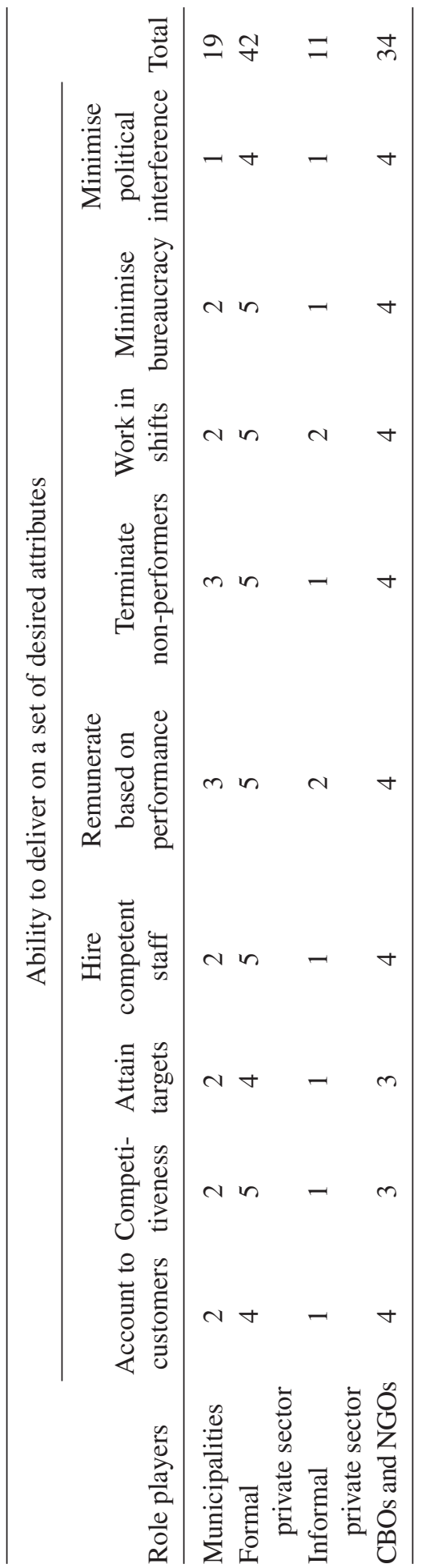


Table 2: Discounted payback analysis.

\begin{tabular}{crrrrr}
\hline & \multicolumn{2}{c}{ Cash flow } & & \multicolumn{2}{c}{ Cumulative cash flow } \\
\cline { 2 - 3 } \cline { 5 - 5 } Year & Undiscounted & Discounted & & Undiscounted & Discounted \\
\hline 1 & -488021 & -443655 & & -488021 & -443655 \\
2 & 1091440 & 90446 & & 603419 & -353209 \\
3 & 2797258 & 2101621 & & 3400677 & 1748412 \\
4 & 4639541 & 3168869 & & 8040218 & 4917281 \\
5 & 6629207 & 41166216 & & 14669425 & 46083497 \\
6 & 8778046 & 4954978 & & 23447471 & 51038475 \\
7 & 11098792 & 5695435 & & 34546263 & 56733910 \\
8 & 13605198 & 6346925 & & 48151461 & 63080835 \\
9 & 16312117 & 6917929 & & 64463578 & 69998764 \\
10 & 19235589 & 7416152 & 83699167 & 77414916 \\
\hline
\end{tabular}

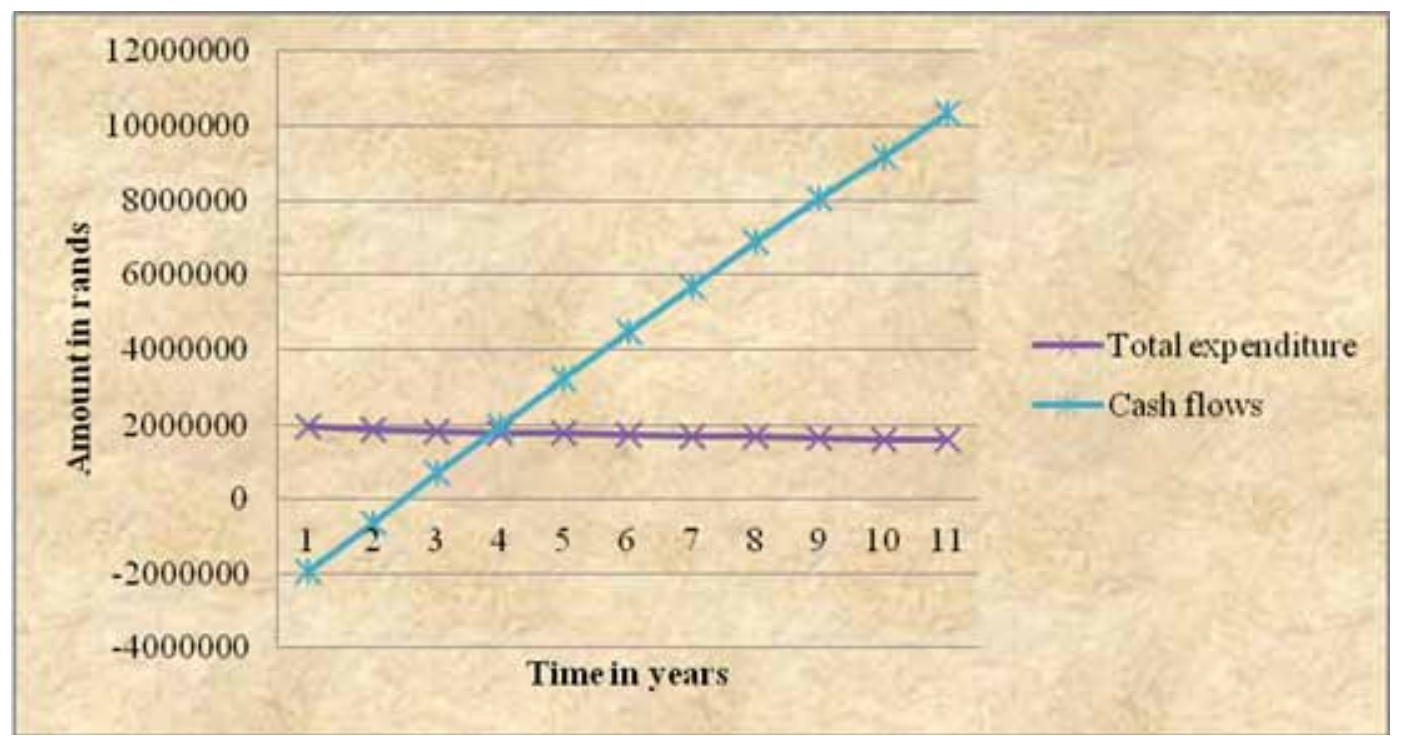

Figure 2: Discounted cash flows projections of proposed project.

The financial analysis of the proposed project indicates that the project will add value to the shareholder's wealth and it has a good expected rate of return $(45.33 \%)$, which is well over $25 \%$ mark that many businesses target [19]. One can therefore confidently state that the proposed project is viable and economically sustainable. However, its success will depend on the capability of the organisation outsourced, the resources available to them and the participation of all stakeholders in waste management. This will be achieved through a joint effort by all stakeholders to minimise the challenges to multi-sector partnerships identified in section 2.5. It is therefore recommended that the:

1. applicants for the partnership should be thoroughly screened to ensure that they:

a. are of impeccable integrity, 
b. have evidence of successful execution of other projects similar in nature and or scale,

c. should be credit worthy and be in a position to pay the equity contribution required by financiers;

2. municipality should ensure that a flawless tendering process is followed in the selection of the successful partner;

3. selected partner should enter into a service delivery agreement with the municipality, which must be drafted in consultation with the municipality;

4. service agreement should be long term, at least 10 years;

5. service delivery agreements should be concise on technical specifications, performance monitoring and penalties for poor performance;

6. agreement should comply with the conditions suggested in section 2.5 of NWU [16];

7. agreement should have a clause for an automatic renewal for one term provided that there is no evidence of poor performance on the part of the service provider;

8. municipality undertakes to collect money from the residents through tariffs and pays for the service rendered, according to the model prescribed in Kadama [4].

It is also recommended that the municipality should involve the public in the entire exercise by seeking their views and updating them on developments. Their active involvement, advisably through elected representatives, is important for the reason that the expected cash inflows of the project will come from tariffs imposed on the public. The public thus needs to actively participate in all preproject activities and in performance monitoring as this will minimise inconsistencies in cash inflows and prompt tariff payments.

The adoption of the proposed change in strategy is likely to result in a number of benefits as elaborated below:

1. A number of jobs, albeit temporary, will be created during the construction of the CWCs. However, one must note that there will also be a number of permanent jobs created.

2. There will be skills transfer during the construction phase and the beneficiaries thereof may apply the acquired skills in other projects.

3. The involvement of all stakeholders in the implementation of the PPP venture will inspire a sense of ownership among the residents, which is very essential for the success of the venture especially where tariff payments and enforcement of by-laws are concerned.

4. The proposed change will minimise the indiscriminate littering and malpractices at the CWCs and the glory of Mafikeng will be restored.

\section{REFERENCES}

[1] MLM. Mafikeng Local Municipality website. http://www.mafikeng.gov.za/, 2010.

[2] Statistics South Africa. Census Super-cross Tables 1996. Pretoria: Statistics South Africa, 2000.

[3] Statistics South Africa. Census Super-cross Tables 2001. Pretoria: Statistics South Africa, 2003.

[4] Kadama, Kizza, Frazer. A comparative analysis of communal waste collection options for Mafikeng City Council. Proceedings of the Fifth International Conference on Waste Management and the Environment, eds Zamorano, Brebbia. Kungolos, Popov \& Itoh, WITPress: Southampton, pp. 215-224, 2010.

[5] Republic of South Africa. 1996. The Constitution of the Republic of South Africa Act No 108 of 1996. Pretoria: Government Printer. [Laws.] 
[6] Republic of South Africa. 2003. Local Government: Municipal Finance Management Act, No 56 of 2003. Pretoria: Government Printer. [Laws.]

[7] Cointreau-Levine, S. \& Coad, A., Guidance pack: Private sector participation in solid municipal waste management, 2000. http://ww2.unhabitat.org/programmes/ump/documents/UMP13.pdf

[8] Lardinois, A. \& van de Klundert., 1995. Private formal and informal sector involvement in municipal solid waste management. Background paper written for the workshop on municipal solid waste management of the Urban Management Programme (UMP), I., Switzerland, 1995, http://www.gdrc.org/uem/waste/swm-finge1.htm

[9] Seader, B. Privatisation moves to the forefront. Solid Waste Power, 3(2), pp. 59-62, 1989.

[10] Hilgendorff, C.C., Emerging Trends in Solid Waste Finance. Solid Waste Power, 3(2), pp. 12-17, 1989.

[11] Shafiul, A.A. \& Syed, M.A., People as partners: Facilitating people's participation in public-private partnerships for solid waste management. Habitat International Journal, 30(4), pp. 781-796, 2006. doi: http://dx.doi.org/10.1016/j.habitatint.2005.09.004

[12] Wikipedia. 2010. Public-private partnerships, http://en.wikipedia.org/wiki/Public-private_ partnership.

[13] PPP unit. 2010. South African public-private partnerships. Document from the National Treasury., http://www.ppp.gov.za/

[14] Kadama, F.R.K., 'An Analysis of the Generation and Management of Domestic Waste in the North West province of South Africa' Ph.D thesis, North West University. 2007.

[15] North West University (NWU) 2009. Draft standard waste management bylaw. Faculty of Law and Centre for Environmental Management document, commissioned by the Office of the Premier of the North West province, South Africa.

[16] Barton, C.R., Leite, L. \& Schertenleib, R., Private Participation in Municipal Solid Waste Service: Experiences in Latin America. Waste Management and Research, 9(6), pp. 495-509, 1991. doi: http://dx.doi.org/10.1016/0734-242X(91)90050-H

[17] Schubelar, P., Wehrle, K. \& Christen, J., Working paper No. 9 Habitat/ World Bank collaborative programme. Conceptual framework for municipal solid waste management in low income countries, 1996.

[18] Firer, C. Ross, S.A., Westerfield, R.W. \& Jordan,B.D., Fundamentals of corporate finance: 3rd South African edition. McGraw-Hill Education: Berkshire, 2004.

[19] Brigham, E.F. \& Gapenski, L.C., Financial management. Theory and practice. The Dryden Press: Orlando Fl, 1994. 